\title{
Empirical Research in Vocational Education and Training Editorial Volume 1 Issue 1 March 2009
}

\author{
Dear readers
}

You are now holding the first issue of the new scientific journal Empirical Research in Vocational Education and Training in your hands. Some of you will certainly ask yourselves whether another scientific journal is needed. True, the number of journals is constantly growing and one can question whether the level of research production is also justification for an increase in the number of publication outlets. What exactly motivated us, then, to add another journal to the existing publishing venues? At least three observations can be cited in support of a new academic publication outlet for research in vocational education and training (VET).

First and foremost is certainly the resurgent interest in vocational education itself as has been observed in political, social and, of course, economic contexts. The expansion of education systems in industrialized countries since the middle of the twentieth century was achieved almost exclusively by extending standard forms of general education through inclusion of a greater proportion of every age cohort and through a general increase in the length of education. In most countries vocationally oriented forms of education were supplanted in importance. Thus impressive progress was made in raising levels of formal education but many problems could nevertheless not be resolved. By the end of the past century at the very latest, this had placed some question marks over the one-sided promotion of general education. Persistently high youth unemployment, over-education, inefficiently long education and training programs, multiple educational programs without any corresponding employment benefits or incremental value in the labour market, the exclusion of academically less talented persons from the formal education system, etc. are but a few of the issues which suggested that perhaps this was not a problem of "too little" education but rather one of misguided education programs and content. As a result, renewed attention is being drawn to vocational education that - using the right approach - is not simply a second-rate kind of education but rather a form of education that is better suited to the needs of the vocational learning community and the job market. However, because many of the existing scientific publication outlets still attach comparatively little significance to VET, it is often difficult for researchers to find editors and reviewers who are open to this topic.

Secondly, whether the given socio-political expectations will be met through a renewed orientation towards vocational education is not an issue that can be simply clarified through political-ideological discourse, nor will analysis of historical data, or the logic of theoretical models based on such data, suffice in answering all the questions as to how to proceed next. What is also needed are empirical studies of existing models and new interventions and experiments with completely new forms of education. The launch of this new journal comes at a time when great strides are being made with regard to the empirical methods applied in social science and psychological research. In conjunction with the increasingly better datasets, this is enabling more precise and more credible conclusions. Until now, most of the existing publications devoted to vocational education attached little importance to empirical and, in particular, quantitative research. One particular aim of this new journal, then, is to serve as a publication outlet for researchers who are conducting vocational education research using modern empirical methods and techniques as well as innovative datasets. In this journal the question of "how" will be accorded as much importance as "what".

Thirdly, any research approach with an extremely narrow focus on one specific scientific discipline will often fail to acknowledge reforms that are practical in implementation and viable in practice. Research that produces useful outputs not only for policymakers and education administrators but also for business enterprises and the individuals seeking VET must not be limited, in an a priori fashion, to a monodisciplinary approach. Instead, the adequate theoretical bases and empirical methods used by researchers should be issue-oriented and problem-based. Which, however, does not mean that this journal ranks itself among the numerous yet not very highly esteemed inter-disciplinary reviews. The research papers 
presented here represent disciplinary scientific research. They are consistent with the standards of the respective discipline, be it psychology, sociology or economics, and should exhibit a quality recognized as state-of-the-art in their discipline. The journal is multi-disciplinary and embraces the same high quality standards as mono-disciplinary-oriented journals.

The philosophy and raison d'etre of the new journal are derived from the three observations cited above and this, we believe, represents a unique combination within the current range of similar journals.

The first five articles give a good impression of the breadth of issues, methods and theoretical foundations covered by Empirical Research in Vocational Education and Training. The journal will thematically cover all elements of VET - the learners, the companies providing training, the vocational school teachers as well as the state as a controlling body (inspectorate; see this issue). Nor must it be forgotten that, in contrast to general education, the issue of corporate-sector funding is of generally greater importance in the field of VET.

Last but not least, in the name of the entire Editorial Board, thanks is given to the Swiss Federal Office for Professional Education and Technology (OPET), without whose generous funding of vocational education research the launch of this journal would not have been possible.

So, dear readers and potential authors, the Editorial Board hopes that this new journal fulfils your high expectations and is looking forward to receiving many comments, suggestions and submissions!

Stefan C. Wolter

Editor-in-chief 